\section{Philippines should not have been included}

The $C M A J$ editorial $^{1}$ by Dr. Kale came to my attention through an editorial by Haroon Siddiqui that appeared in The Toronto Star on Jan. 18, 2012.'

Siddiqui commented that Dr. Kale, in reference to female feticide, said that people from China, Korea, Vietnam and the Philippines "have imported the wretched practice into Canada." This of course was nothing more than twisting Dr. Kale's words. Dr. Kale did say, "We should, however, avoid painting all Asians with the same broad brush and doing injustice to those who are against sex selection."

I object to the Philippines being included in either editorial. The Philippines is a devoutly Catholic country and the practice of sex selection by abortion is generally unacceptable.

I have been associated with the Philippines for over 20 years and I am married to a Filipina. I have shown Siddiqui's editorial to a number of our Filipino friends and all are very offended.

I would suggest removing any reference to the Philippines as it is the worst possible example of a country where sex-selective abortion might take place.

I applaud Dr. Kale for once again bringing this issue to the attention of the world. Although female feticide is "old news," reminding the main offenders (India and China) that their actions are unacceptable is obviously a good thing.

\section{Richard East}

Mississauga, Ont.

\section{Reference}

1. Kale R. "It's a girl!" - could be a death sentence. CMAJ 2012; 184:387-8

2. Siddiqui H. Orientalist discourse on female feticide in Canada. Toronto Star 2012 Jan. 18.

CMAJ 2012. DOI:10.1503/cmaj.112-2047

\section{Dr. Kale responds}

Some misunderstanding ${ }^{1}$ has arisen as a result of one of the statements in my editorial. $^{2}$

I referred to a 2010 study in which Asians were defined, for the purposes of that study, as "people from India, China, Korea, Vietnam and Philip- pines." ${ }^{\prime 3}$ I did not intend to suggest that the results (e.g., evidence of sex selection, disparity of infant sex) applied to all those groups; indeed, the results were varied.

I apologize for the ambiguity.

\section{Rajendra Kale MD}

\section{Reference}

1. East R. Philippines should not have been included [letter]. CMAJ 2012;184;1065.

2. Kale R. "It's a girl!" - could be a death sentence. CMAJ 2012; 184:387-8.

3. Almond D, Edlund L, Milligan KO. O Sister, where art thou? The role of son preference and sex choice: evidence from immigrants to Canada. NBER Working Paper No. 15391. Cambridge (MA): The National Bureau of Economic Research; 2009, revised Oct. 2010.

CMAJ 2012. DOI:10.1503/cmaj.112-2048

\section{Infection control in the emergency department}

We read with interest the articles by Leis and Gold, ${ }^{1}$ and by Mumoli and Cei. ${ }^{2}$ Infection control procedures should have been mentioned in the article by Leis and Gold entitled "Management of community-acquired pneumonia in the emergency department." Emergency departments are high-risk areas for disease transmission because they are often overcrowded, and infectious or susceptible patients may wait in proximity to one another for several hours. ${ }^{3}$ In another CMAJ article, Quach and colleagues $^{4}$ report a 3.9 odds ratio for the risk of gastrointestinal and respiratory infections among elderly residents of long-term care facilities following a visit to the emergency department. Similar findings have been described in other populations. ${ }^{5}$ The role of emergency departments in disease transmission dramatically emerged during the outbreak of severe acute respiratory syndrome (SARS). ${ }^{6}$ Subsequently, the US Centers for Disease Prevention and Control and the World Health Organization issued new infection control guidelines that introduced respiratory hygiene and cough etiquette measures (e.g., covering of nose and mouth possibly with disposable surgical mask, adequate distancing among patients and careful application of hand hygiene) as part of standard precautions to be applied in all health care settings, to all patients with cough and other respiratory symptoms. ${ }^{7.8} \mathrm{~A}$ rigorous application of this set of infection control measures, including isolation if indicated, may significantly reduce the risk of disease transmission in emergency departments, thus protecting health care workers, patients and visitors. Mention about it should be included in all basic sets of indications for the management of community-acquired pneumonia in emergency departments.

\section{Francesco M. Fusco MD, Vincenzo \\ Puro MD}

National Institute for Infectious Diseases

"L Spallanzani," Rome, Italy

\section{References}

1. Leis JA, Gold WL. Management of communityacquired pneumonia in the emergency department. CMAJ 2012;184:559.

2. Mumoli N, Cei M. Community-acquired pneumonia. CMAJ 2012;184:560.

3. Rothman RE, Irvin CB, Moran GJ, et al. Respiratory hygiene in the emergency department. [published erratum appears in Ann Emerg Med 2007; 49:61]. Ann Emerg Med 2006;48:570-82.

4. Quach C, McArthur M, McGeer A, et al. Risk of infection following a visit to the emergency department: a cohort study. CMAJ 2012;184:E232-9.

5. Farizo KM, Stehr-Green PA, Simpson DM, et al Pediatric emergency room visits: a risk factor for acquiring measles. Pediatrics 1991;87:74-9.

6. Chen YC, Huang LM, Chan CC, et al. SARS in hospital emergency room. Emerg Infect Dis 2004; 10:782-8.

7. Siegel JD, Rhinehart E, Jackson M, et al. 2007 guideline for isolation precautions: preventing transmission of infectious agents in healthcare settings. Atlanta (GA): Centers for Disease Control and Prevention; 2007. Available: www.cdc.gov/hicpac /2007ip/2007isolationprecautions.html (accessed 2012 Feb. 06)

8. World Health Organization. Infection prevention and control of epidemic-and pandemic-prone acute respiratory diseases in health care. Geneva (Switzerland): The Organization; 2007. Available: www.who.int/csr /resources/publications/WHO_CD_EPR_2007_6/en/ (accessed 2012 Feb. 06).

CMAJ 2012. DOI:10.1503/cmaj.112-2038

\section{Letters to the editor}

In submitting a letter, you automatically consent to have it appear online and/or in print. All letters accepted for print will be edited by $C M A J$ for space and style. Most references and multiple authors' names, full affiliations and competing interests will appear online only. (The full version of any letter accepted for print will be posted at cmaj.ca.) 